\title{
Effect of different feed restriction regimens on lamb performance and carcass traits
}

\author{
Mohamed Abouheif ${ }^{1}$, Hussain Al-Sornokh ${ }^{1}$, Ayman Swelum ${ }^{1,2}$, Hilal Yaqoob ${ }^{1}$, \\ Abdullah Al-Owaimer ${ }^{1}$
}

\begin{abstract}
${ }^{1}$ King Saud University, College of Food and Agriculture Sciences, Department of Animal Production, Riyadh, Saudi Arabia. ${ }^{2}$ Zagazig University, Department of Theriogenology, Zagazig, Sharkia Province, Egypt.
\end{abstract}

\begin{abstract}
Fifty Najdi ram lambs weighing an average of $38.1 \pm 0.5 \mathrm{~kg}$ were utilized in this study to determine the effects of feed restriction level with or without subsequent realimentation on lamb performance and carcass composition. Lambs were allotted randomly and equally into five groups. The groups were fed a control diet ad libitum; two groups fed 0.90 and 0.80 of ad libitum intake throughout the eight-week period of the trial (R), and two groups fed 0.90 and 0.80 of ad libitum intake for a six-week period followed by two weeks of realimentation (RR). All lambs were slaughtered after eight weeks of experimentation. Average daily gain (ADG) for the 0.90 and 0.80 ad libitum groups decreased by 7.6 and $26.9 \%$ during restriction, whereas the lambs during realimentation period had 35 and $30.5 \%$ faster ADG and 27.5 and $21.8 \%$ better feed:gain ratios than the control, respectively. At the end of the trial, final, empty and hot carcass weights and overall ADG of the 0.90 ad libitum RR group did not differ from control. Feeding performance values of the 0.80 ad libitum $\mathrm{R}$ group were the lowest among the treatments. The studied feed restriction regimens depressed the weights of empty stomach, tail fat, visceral fat, and subcutaneous fat; however, two weeks of realimentation were not enough to induce complete weight recovery in these tissues. The 0.90 ad libitum RR restriction routine can be adopted as a nutritional management practice for fattening Najdi lambs.
\end{abstract}

Key Words: body composition, compensatory growth, limit-feeding, sheep

\section{Introduction}

Livestock enterprises in Saudi Arabia are likely to depend almost entirely on imported feed ingredients. To mitigate the increasing costs of feeds and to make lamb production profitable, efforts have been made to investigate possible strategies to reduce the cost of production through the imposition of feed restriction followed by compensatory growth (Al-Selbood, 2009; Abouheif et al., 2013). Compensatory growth is manifested in the feedingestion ability of previously restricted animals to outgain their better counterparts when given free access to good quality feed. Compensatory growth may be associated with lower maintenance energy requirements brought about by reducing liver and gut masses and protein turnover (Mahouachi and Atti, 2005; Shadnoush et al., 2011), an increase in the growth efficiency, and changes in body composition (Kamalzadeh et al., 2009). The response varies according to the breed, duration and severity of restriction, duration of realimentation, quality of the diet and stage of

Received July 20, 2014 and accepted January 9, 2015

Corresponding author: abouheif@yahoo.com

http://dx.doi.org/10.1590/S1806-92902015000300001

Copyright $(2015$ Sociedade Brasileira de Zootecnia. This is an Open Access article distributed under the terms of the Creative Commons Attribution Non-Commercial License, which permits unrestricted non-commercial use, distribution, and reproduction in any medium, provided the original work is properly cited. development at the start of restriction (Al-Selbood, 2009). Abouheif et al. (2013) found that compensatory growth was better expressed when feed restriction occurred at 36 than $30 \mathrm{~kg}$ body weight in indigenous Najdi sheep from Saudi Arabia. There are conflicting results about the amount of feed intake after a period of feed restriction; some authors reported a significant increase in feed intake (Homem Junior et al., 2007; Dashtizadeh et al., 2008), whilst others reported no significant difference (Mahouachi and Atti, 2005; Shadnoush et al., 2011).

Experiments conducted with various classes of ruminants to evaluate the influences of different feeding restrictions on animal performance have generated conflicting results. Several reports have shown that there are no differences in body composition between ad libitum and realimented steers (Rompala et al., 1985) and sheep (Marais et al., 1991). Drouillard et al. (1991) found an increase in body fat content, whilst others have reported increases in the lean tissue of the compensated goats (Dashtizadeh et al., 2008) and lambs (Atti and Ben Salem, 2008; Al-Selbood, 2009; Abouheif et al., 2013) in comparison with the controlfed animals. The discrepancies could be due to different intensities and durations of restriction before realimentation, and breed types with different maturity ages (Tolla et al., 2003). However, knowledge of the effects of feed restriction and compensation on feeding performance and carcass 
composition can help in developing strategies to optimize the use of feedstuffs by sheep producers. The objective of this study was to evaluate the effect of nutritional restriction level with or without subsequent realimentation during the final two weeks before slaughtering on performance and carcass composition in Najdi sheep breed.

\section{Material and Methods}

A total of fifty Najdi male lambs with an average body weight of $33.1 \pm 0.5 \mathrm{~kg}$ and at approximately four months of age were selected for this study. The experimental protocol regarding the care and handling of lambs had been approved by the Ethics Committee of the king Saud University, Riyadh, Kingdom of Saudi Arabia. Lambs were purchased from a local farm. Upon arrival, lambs were individually weighed, identified, vaccinated against endemic infectious diseases, injected against internal and external parasites, and a recommended dose of vitamins $\mathrm{AD}_{3} \mathrm{E}$ injection was given. Thereafter, lambs were randomly assigned to one of five equal groups with ten lambs in each group. Each group housed in five pens (replicates) with two lambs per pen; the pen was used as an experimental unit for feed performance data. Pens were $1.7 \times 3.0 \mathrm{~m}$ and constructed of metal gates and concrete floors, located under a roof in an open-sided barn.

All groups were fed a commercial pellet ad libitum for three weeks as an adaptation period; the experimental trial started thereafter. The experimental lambs were allotted randomly in a $2 \times 2+1$ factorial arrangement with two levels of intake restriction ( 0.90 and 0.80 of ad libitum), two-restriction regimens (with and without realimentation), and a common positive ad libitum control. The first feeding group was used as a common control and fed ad libitum throughout the eight-week experimental trial. The second and fourth feeding groups (R) were subjected to continuous feed restriction at 0.90 and 0.80 of ad libitum intake, respectively, up to the end of the trial. The third and fifth feeding groups (RR) were subjected to six weeks of feed restriction at 0.90 and 0.80 of ad libitum intake, respectively, followed by a two-week period of ad libitum feeding. Feeding levels of restricted groups were calculated by determining the average DMI of the lambs with ad libitum access to feed the previous week and multiplying that average by 0.90 and 0.80 to determine the amounts of feed to offer to lambs in the 0.90 and 0.80 restriction groups, respectively.

All groups were fed once daily at 09.00 after discarding the refusals from the previous day. Refusals were weighed and sampled for DM determination before discarding. Feeding and management practices were applied equally to all experimental groups. The commercial pellet was formed as a pelleted total-mixed ration with a ratio of $75 \%$ concentrate: $25 \%$ alfalfa hay. Pellets were randomly subsampled immediately prior to feeding; samples were then composited across the feeding trial period and subsequently ground to pass a 2-mm screen. Feed composites were dried in a forced-air oven at $50{ }^{\circ} \mathrm{C}$ until they attained a constant weight before chemical analyses. Feeds were analyzed for CP, EE, ash, Ca and P according to AOAC (1995). Neutral detergent fiber and ADF were determined according to Van Soest et al. (1991). The chemical composition (DM basis) was $14.53 \% \mathrm{CP}, 1.16 \% \mathrm{EE}, 24.91 \% \mathrm{NDF}, 14.22 \%$ ADF, $0.54 \% \mathrm{Ca}, 0.31 \% \mathrm{P}$, and $7.46 \%$ ash. All pens were supplemented with trace-mineral mixture blocks. The experimental period lasted eight weeks, during which DM intake and lamb weight data were recorded weekly; lamb weight was recorded after $12 \mathrm{~h}$ fasting and before feeding in the morning. Fresh drinking water was freely available at all times.

At the end of the feeding trial, all lambs were slaughtered in a commercial abattoir after fasting for $18 \mathrm{~h}$. The gastrointestinal tract was collected, weighed full and empty to calculate empty body weight, and separated into stomach compartments (rumen, reticulum, omasum, and abomasum) and intestines (small and large intestines). Hot carcass, liver, empty stomach compartments, empty intestines, and internal visceral fat were weighed immediately after dressing. Carcasses were then chilled at $4{ }^{\circ} \mathrm{C}$ for $24 \mathrm{~h}$ and weighed (cold carcass); thereafter, the carcasses were carefully split longitudinally into two equal halves by sawing down along the dorsal midline.

The right side of each carcass was physically separated into subcutaneous fat, intermuscular fat, tail fat, lean and bone (bone plus cartilage and major tendons) components; the weights of separated components were recorded. The lean tissue was ground through a 4-mm plate, mixed, and reground again. During the second grinding, five subsamples (10-15 g) were taken from each carcass and mixed thoroughly to obtain a 50-75-g sample that was placed in a plastic bag, frozen and stored at $-20{ }^{\circ} \mathrm{C}$ pending chemical analysis. Ground lean samples were analyzed for moisture, ash, ether extract and protein according to AOAC (1995).

Data for growth performance, visceral fat weights and carcass composition were statistically analyzed using PROC MIXED procedures of SAS (Statistical Analysis System, version 8). The statistical model was:

$$
\mathrm{Y}_{i j k}=\mu+\tau_{i}+\mathrm{p}_{i j}+\mathrm{e}_{i j k}
$$

in which $\mathrm{Y}_{i j k}=$ observation of the $k$-th animal in the $j$-th pen receiving the $i$-th nutritional treatment $(k=1,2, j=1,2, .$. , 5 , and $i=1,2, \ldots, 5) ; \mu=$ overall mean; $\tau_{i}=$ fixed effect of 
the $i$-th nutritional treatment (control, 0.90 ad libitum $\mathrm{R}$, 0.90 ad libitum RR, 0.80 ad libitum $\mathrm{R}$, and 0.80 ad libitum $\mathrm{RR}) ; \mathrm{p}_{i j}=$ random effect of $j$-th pen in the $i$-th nutritional treatment; and $\mathrm{e}_{i j k}=$ random error associated with each observation. Duncan's multiple range test was used to test for significant differences between means. To calculate the main effects of restriction level (0.90/0.80 ad libitum), restriction regime $(\mathrm{R} / \mathrm{RR})$ and their interaction, the following model was utilized:

$$
\mathrm{Y}_{i j k}=\mu+\tau_{i}+\rho_{j}+\tau \rho_{i j}+\mathrm{e}_{i j k}
$$

in which $\mathrm{Y}_{i j k}=$ observation of the $k$-th animal in the $j$-th restriction regimen receiving the $i$-th restriction level; $\mu=$ overall mean; $\tau_{i}=i$-th restriction level; $\rho_{j}=j$-th restriction regimen; $\tau \rho_{i j}=$ interaction; $\mathrm{e}_{i j k}=$ experimental error.

\section{Results}

The average actual feed intakes during the restriction period (Table 1) for the 0.90 and 0.80 ad libitum groups were 89.6 and $79.7 \%$ of the ad libitum feed intake, respectively. During the restriction period, average daily gain (ADG) decreased $(\mathrm{P}<0.01)$ as the level of feed restriction was increased; in comparison with the ad libitum control group, the ADG decreased by 7.6 and $26.9 \%$ for the 0.90 and 0.80 ad libitum-fed groups, respectively. Feed:gain ratios (FG) for the control and the 0.90 ad libitum groups did not differ significantly $(\mathrm{P}>0.01)$, whereas the $\mathrm{FG}$ for the ad libitum control group averaged 9.7\% more than the 0.80 ad libitum-fed groups $(\mathrm{P}<0.01)$. In general, an average of $13 \%$ depression $(\mathrm{P}<0.01)$ in $\mathrm{FG}$ was noted for the 0.80 ad libitum in comparison with the 0.90 ad libitum-fed lambs.

The 0.90 and 0.80 ad libitum realimented lambs (RR) gained daily weight and converted feed similarly $((\mathrm{P}>0.01)$ during the realimentation period, but were 35 and $30.5 \%$ faster $(\mathrm{P}<0.01)$ in $\mathrm{ADG}$, and 27.5 and $21.8 \%$ more efficient in FG $(\mathrm{P}<0.01)$ than the control lambs, respectively. The 0.90 and 0.80 ad libitum realimented lambs (RR) consumed daily dry matter (DMI) similarly $(\mathrm{P}>0.01)$ to the control lambs during the two-week realimentation period.

The final weight and overall ADG of lambs fed 0.90 ad libitum and realimented during the final two weeks of the trial $(\mathrm{RR})$ were not different $(\mathrm{P}>0.01)$ compared with the control lambs, whereas the final weight, ADG, and DMI of the lambs from the continuous $0.80 \mathrm{ad}$ libitum $(\mathrm{R})$ group were the lowest $(\mathrm{P}<0.01)$ among other treatment groups. Lambs in the 0.90 ad libitum of the RR treatment had significantly $8 \%$ lower $(\mathrm{P}<0.01)$ overall DMI throughout the feeding trial than the control group. In addition, the former 0.90 ad libitum RR lambs were the most efficient in overall FG in comparison with other treatments.

At the end of the trial, weights of empty body and hot carcass for the 0.90 ad libitum $\mathrm{R}$ and RR groups (Table 2) approached those of the control group. Continuous feed

Table 1 - Feeding performance of growing lambs during the different experimental periods

\begin{tabular}{|c|c|c|c|c|c|c|c|c|c|}
\hline \multirow{2}{*}{ Trait } & \multirow{2}{*}{ Control } & \multicolumn{2}{|c|}{0.90 of ad libitum } & \multicolumn{2}{|c|}{0.80 of ad libitum } & \multirow{2}{*}{ SEM } & \multirow{2}{*}{0.90 vs. $0.80^{1}$} & \multirow{2}{*}{ R vs. $\mathrm{RR}^{1}$} & \multirow{2}{*}{ Interaction } \\
\hline & & $\mathrm{R}$ & RR & $\mathrm{R}$ & RR & & & & \\
\hline \multicolumn{10}{|c|}{ (pre-restriction) } \\
\hline Weight, kg & 33.11 & 33.57 & 33.09 & 33.07 & 33.11 & 0.33 & 0.451 & 0.532 & 0.345 \\
\hline ADG, g. $d^{-1}$ & 246 & 249 & 246 & 252 & 258 & 7.81 & 0.601 & 0.541 & 0.416 \\
\hline DMI, g.d $d^{-1}$ & 1553 & 1565 & 1556 & 1573 & 1586 & 32.23 & 0.369 & 0.266 & 0.443 \\
\hline Feed:gain, g.g ${ }^{-1}$ & 6.31 & 6.34 & 6.33 & 6.19 & 6.29 & 0.19 & 0.632 & 0.542 & 0.369 \\
\hline \multicolumn{10}{|c|}{ Weeks 1-6 (restriction) } \\
\hline Initial weight, $\mathrm{kg}$ & 38.28 & 38.80 & 38.26 & 38.36 & 38.44 & 0.61 & 0.411 & 0.432 & 0.412 \\
\hline ADG, g.d $\mathrm{d}^{-1}$ & $236 a$ & $217 b$ & $219 b$ & $171 \mathrm{c}$ & $174 \mathrm{c}$ & 10.13 & 0.007 & 0.456 & 0.163 \\
\hline DMI, g.d $d^{-1}$ & $1683 a$ & $1511 b$ & $1508 b$ & $1340 \mathrm{c}$ & $1342 \mathrm{c}$ & 89.24 & 0.008 & 0.345 & 0.094 \\
\hline Feed:gain, g.g ${ }^{-1}$ & $7.13 b$ & $6.95 b$ & $6.89 b$ & $7.85 \mathrm{a}$ & $7.80 \mathrm{a}$ & 0.45 & 0.010 & 0.442 & 0.183 \\
\hline Final weight, kg & $48.15 a$ & $47.51 \mathrm{a}$ & $47.35 \mathrm{a}$ & $45.54 b$ & $45.65 b$ & 1.93 & 0.004 & 0.193 & 0.086 \\
\hline \multicolumn{10}{|c|}{ Weeks 7-8 (realimentation) } \\
\hline ADG, g.d ${ }^{-1}$ & $206 b$ & $151 \mathrm{c}$ & $278 \mathrm{a}$ & $148 \mathrm{c}$ & $269 a$ & 8.31 & 0.011 & 0.008 & 0.063 \\
\hline DMI, g.d ${ }^{-1}$ & $1700 \mathrm{a}$ & $1595 b$ & $1665 a$ & $1415 \mathrm{c}$ & $1670 \mathrm{a}$ & 73.14 & 0.003 & 0.010 & 0.112 \\
\hline Feed:gain, g.g ${ }^{-1}$ & $8.25 b$ & $10.56 \mathrm{a}$ & $5.98 \mathrm{c}$ & $9.56 \mathrm{a}$ & $6.45 \mathrm{c}$ & 0.55 & 0.008 & 0.004 & 0.742 \\
\hline Final weight, kg & $51.03 \mathrm{a}$ & $49.48 b$ & $51.41 \mathrm{a}$ & $47.61 \mathrm{c}$ & $49.26 b$ & 2.11 & 0.036 & 0.044 & 0.043 \\
\hline \multicolumn{10}{|c|}{ Weeks 1-8 (overall period) } \\
\hline ADG, g.d ${ }^{-1}$ & $229 a$ & $207 \mathrm{~b}$ & $241 \mathrm{a}$ & $165 c$ & $200 \mathrm{~b}$ & 6.52 & 0.006 & 0.005 & 0.008 \\
\hline DMI, g.d $\mathrm{d}^{-1}$ & $1687 \mathrm{a}$ & $1530 \mathrm{~b}$ & $1552 b$ & $1361 d$ & $1423 c$ & 65.28 & 0.029 & 0.631 & 0.036 \\
\hline Feed:gain, g.g-1 & $7.37 \mathrm{~b}$ & $7.39 \mathrm{~b}$ & $6.44 \mathrm{c}$ & $8.25 \mathrm{a}$ & $7.20 \mathrm{~b}$ & 0.19 & 0.043 & 0.036 & 0.010 \\
\hline
\end{tabular}

Control $=$ ad libitum feeding from week 1 to $8 ; \mathrm{R}=0.80$ or 0.90 of the ad libitum feed intake from week 1 to $8 ; \mathrm{RR}=0.80$ or 0.90 of the ad libitum feed intake from week 1 to 6 followed by 2 weeks (weeks 7 and 8 ) of ad libitum realimentation feeding; SEM - standard error of the mean.

ADF - average daily gain; DMI - dry matter intake.

${ }^{1}$ Effect of restriction level $(0.90 / 0.80$ ad libitum), restriction regimen (RR/R), and their interaction; probability values.

a,b,c,d Means in the same row with different letters differ $(\mathrm{P}<0.01)$. 
restriction at 0.80 of ad libitum (R) caused 4.6 and $7.4 \%$ depressions $(\mathrm{P}<0.01)$ in the weights of empty body and hot carcass in comparison with the control group, respectively. Feeding restriction treatments did not have any impacts on dressing percentage and empty intestinal weight, whereas feeding restriction treatments depressed $(\mathrm{P}<0.01)$ the weights of the empty stomach compartments; the highest weight depression was $14.5 \%$ in the 0.80 ad libitum $\mathrm{R}$ group.

Continuous feed restriction (R) depressed the weight of liver by an average of $21.3 \%$, but this lost weight was fully compensated during the two-week period of realimentation. Weights of tail and visceral fats reduced $(\mathrm{P}<0.01)$ during the feed restriction period and were unable to recover the lost weights during the realimentation. The highest weight depressions were 24.1 and $35.5 \%$ for tail and visceral fats, respectively in the 0.80 ad libitum $\mathrm{R}$ group, whereas the corresponding depressions averaged 16.7 and $31.1 \%$ in the other treatments in comparison with control.

Subcutaneous fat from the 0.90 and 0.80 ad libitum-fed lambs was lighter $(\mathrm{P}<0.01)$ than the control; there was no variation in responses due to the level of restriction and the feeding regimens. The reduction in subcutaneous fat weight averaged $23.3 \%$ compared with the control group. Realimented lambs (RR) fed 0.90 or 0.80 of ad libitum levels had higher $(\mathrm{P}<0.01)$ carcass lean weight; they had an average of $8 \%$ more lean mass in their carcasses than the control lambs. On the other hand, lambs that were not realimented and continued on 0.90 or 0.80 ad libitum regimens $(\mathrm{R})$ had similar carcass lean weights compared with control lambs. Percentages of protein, moisture, ether extract (intramuscular fat) and ash in the carcass lean did not differ $(\mathrm{P}>0.01)$ between control, $\mathrm{RR}$ and $\mathrm{R}$ groups.

\section{Discussion}

The effect of DMI restriction on lamb performance has been studied (Mahouachi and Atti, 2005; Kamalzadeh et al., 2009). Regarding lambs fed ad libitum, lambs held to less than maximal DMI had reduced ADG as a function of the plane of nutrition, thereby resulting in inadequate intake of nutrients required to sustain normal growth and development (Dashtizadeh et al., 2008; Abouheif et al., 2013). During the two-week period of realimentation, lambs had improved ADG (Al-Selbood, 2009; Abouheif et al., 2013) and improved FG (Homem Junior et al., 2007; Shadnoush et al., 2011). This higher gain could not be attributed to DMI because intake values were not different between realimented (RR) and control groups, but possibly due to the better FG in realimented lambs and/or the decreased heat production during the restriction and its continuation during realimentation (Yambayamba et al., 1996). These results are in agreement with those of Mahouachi and Atti (2005), but not with those of Homem Junior et al. (2007), who reported that rapid gain during realimentation was associated with increased feed intake. The apparent

Table 2 - Body and carcass composition at the end of the trial

\begin{tabular}{|c|c|c|c|c|c|c|c|c|c|}
\hline \multirow{2}{*}{ Trait } & \multirow{2}{*}{ Control } & \multicolumn{2}{|c|}{0.90 of ad libitum } & \multicolumn{2}{|c|}{0.80 of ad libitum } & \multirow{2}{*}{ SEM } & \multirow{2}{*}{0.90 vs. $0.80^{1}$} & \multirow{2}{*}{ R vs. RR ${ }^{1}$} & \multirow{2}{*}{ Interaction $^{1}$} \\
\hline & & $\mathrm{R}$ & $\mathrm{RR}$ & $\mathrm{R}$ & $\mathrm{RR}$ & & & & \\
\hline Empty body, kg & $45.6 \mathrm{a}$ & $44.7 \mathrm{ab}$ & $45.8 \mathrm{a}$ & $43.5 b$ & $43.3 b$ & 1.94 & 0.005 & 0.432 & 0.205 \\
\hline Hot carcass, kg & $25.6 \mathrm{a}$ & $26.3 \mathrm{ab}$ & $25.2 \mathrm{a}$ & $23.7 b$ & $24.2 \mathrm{ab}$ & 0.84 & 0.041 & 0.038 & 0.316 \\
\hline Dressing, $\%$ & 49.7 & 49.0 & 49.1 & 49.7 & 50.2 & 0.64 & 0.651 & 0.531 & 0.693 \\
\hline Empty stomach, kg & $1.59 \mathrm{a}$ & $1.49 \mathrm{~b}$ & $1.43 b$ & $1.36 \mathrm{c}$ & $1.45 \mathrm{bc}$ & 0.08 & 0.004 & 0.051 & 0.167 \\
\hline Empty intestine, $\mathrm{kg}$ & 1.29 & 1.18 & 1.23 & 1.19 & 1.22 & 0.05 & 0.423 & 0.385 & 0.089 \\
\hline Liver, kg & $1.20 \mathrm{a}$ & $0.96 \mathrm{~b}$ & $1.22 \mathrm{a}$ & $0.93 b$ & $1.18 \mathrm{a}$ & 0.09 & 0.048 & 0.415 & 0.113 \\
\hline Tail fat, kg & $3.81 \mathrm{a}$ & $3.12 \mathrm{bc}$ & $3.25 b$ & $2.89 \mathrm{c}$ & $3.15 b c$ & 0.15 & 0.008 & 0.417 & 0.009 \\
\hline Visceral fat, kg & $4.82 \mathrm{a}$ & $3.21 \mathrm{~b}$ & $3.40 \mathrm{~b}$ & $3.11 \mathrm{~b}$ & $3.35 b$ & 0.24 & 0.268 & 0.239 & 0.236 \\
\hline \multicolumn{10}{|l|}{ Separable tissue $^{2}$} \\
\hline Subcutaneous, kg & $2.11 \mathrm{a}$ & $1.55 \mathrm{~b}$ & $1.73 b$ & $1.54 \mathrm{~b}$ & $1.65 b$ & 0.18 & 0.251 & 0.368 & 0.411 \\
\hline Intermuscular, $\mathrm{kg}$ & 1.05 & 1.12 & 1.12 & 1.14 & 1.08 & 0.06 & 0.331 & 0.267 & 0.385 \\
\hline Lean, $\mathrm{kg}$ & $5.02 b$ & $5.13 b$ & $5.35 \mathrm{a}$ & $5.05 b$ & $5.49 \mathrm{a}$ & 0.13 & 0.512 & 0.492 & 0.142 \\
\hline Bone, $\mathrm{kg}$ & 2.43 & 2.53 & 2.57 & 2.48 & 2.41 & 0.09 & 0.331 & 0.415 & 0.368 \\
\hline \multicolumn{10}{|l|}{ Lean composition ${ }^{3}$} \\
\hline Protein, $\%$ & 15.9 & 16.5 & 16.1 & 16.3 & 15.9 & 0.44 & 0.258 & 0.364 & 0.417 \\
\hline Ether extract, \% & 17.3 & 16.6 & 16.8 & 16.0 & 16.2 & 0.57 & 0.159 & 0.217 & 0.322 \\
\hline Moisture, $\%$ & 65.7 & 65.9 & 66.1 & 66.7 & 66.8 & 0.84 & 0.254 & 0.351 & 0.289 \\
\hline Ash, $\%$ & 1.1 & 1.0 & 1.0 & 1.0 & 1.1 & 0.01 & 0.621 & 0.458 & 0.229 \\
\hline
\end{tabular}

Control = ad libitum feeding from week 1 to $8 ; \mathrm{R}=0.80$ or 0.90 of the ad libitum feed intake from week 1 to $8 ; \mathrm{RR}=0.80$ or 0.90 of the ad libitum feed intake from week 1 to 6

followed by 2 weeks (weeks 7 and 8 ) of ad libitum realimentation feeding; SEM - standard error of the mean.

${ }_{1}^{1}$ Effect of restriction level $(0.90 / 0.80$ ad libitum $)$, regimen routine (RR/R), and their interaction; probability values.

${ }^{2}$ Physical separation of the carcass right side.

${ }^{3}$ Chemical composition of the separable lean from the carcass right side.

$\mathrm{a}, \mathrm{b}, \mathrm{c}$ Means in the same row with different letters differ $(\mathrm{P}<0.01)$. 
inconsistency may be explained by the differences in levels of restriction and realimentation, composition of diets, age of animal, and periods of restriction and realimentation (Tolla et al., 2003). At the end of the trial, the overall results showed that 0.90 ad libitum feeding followed by a two-week period of realimentation induced complete catchup for body weight. In contrast, 0.80 ad libitum feeding with realimentation (RR) noticeably was unable to fully compensate, and continued to result in lighter body weight than control. However, the trends of weight recovery after feed realimentation in growing lambs probably depended on the duration of the realimentation period. Abouheif et al. (2013) found that $0.75 \mathrm{ad}$ libitum restriction followed by four weeks of realimentaton resulted in almost complete recovery of the lost body weight.

Feeding restriction treatments did not have any effect on empty intestinal tissue weights, whereas it depressed the weights of empty stomach compartments. Several studies have showed decreases in the weights of empty stomach compartments due to restriction treatments (Mora et al., 1996; Yambayamba et al., 1996; Dashtizadeh et al., 2008). Similar results were reported by Hambly and Speakman (2005), who found that with less food entering the digestive system, the weight of the stomach tissue was significantly lower during the $20 \%$ dietary restriction than in control feeding without altering the ability to process the diet. On the other hand, the depression in liver weight during the restriction period was fully recovered during the two-week period of realimentation. The noticeable depression in liver weight during restriction was probably related to a decrease in oxygen consumption by the liver and hepatic blood flow (Burrin et al., 1989). Also, it has been shown that moderate feed restriction resulted in appreciable changes in the metabolism of the liver tissue (Tovar-Luna et al., 2007). In other reports, liver weight was not affected by a period of feed restriction followed by realimentation (Mahouachi and Atti, 2005; Shadnoush et al., 2011; Abouheif et al., 2013). The high growth rate for liver tissue exhibited by compensatory-grown lambs probably reflects hypertrophy of the liver tissue upon realimentation after a period of growth restriction (Sami et al., 2013). This compensatory growth was explained by Mora et al. (1996), who found that during the first period of realimentation, energy was diverted mainly to replenish protein and glycogen reserves in the liver tissue. In addition, Wester et al. (1995) reported that livers of lambs were completely replenished in two days, but according to Ryan et al. (1993), the liver of cattle and sheep were replenished in 90 days. Abouheif et al. (2013) indicated that liver and stomach tissues of lambs weighing $36 \mathrm{~kg}$ and fed 0.75 or 0.60 ad libitum levels required four weeks of realimentation to induce reversible growth restriction with complete catch-up growth.

Depression in tail, visceral, and subcutaneous fat weights due to feed restriction treatments has been reported in the literature. Drouillard et al. (1991) found that weights of internal fat depots were dramatically affected by restriction and did not recover after realimentation. In addition, Abouheif et al. (2013) found that exposing lambs to feed restriction caused a depression in fat deposition in tail depot; the highest reduction was $26.9 \%$ for the lambs fed $60 \%$ of ad libitum intake followed by a four-week period of realimentation. Marais etal.(1991) and Sami etal. (2013) found that various restriction regimens depressed the accumulation of body and carcass fat in realimented lambs because the magnitude of fat increases during the realimentation was not large enough to better or equal the fat contents of the ad libitum control lambs. In general, the observed depression percentages for the visceral fat were greater than tail and subcutaneous fats, indicating that internal visceral fat depots were more responsive to restriction treatments than tail and subcutaneous fat depots. However, these results probably indicate that the mobilization of tail and subcutaneous fats as sources of energy during the feeding restriction period were slightly delayed, leaving the visceral fat as an immediate source of energy utilization. This is partially in agreement with Al-Selbood (2009), who acknowledged the adaptation capacity of the fat-tailed Najdi sheep to feed shortage, and the importance of the tail fat as a mobilizing source for the generation of energy at higher levels of malnutrition. This could be especially important for sheep grazing in arid and semiarid areas where dry periods can last for months and feed availability is therefore limited. Furthermore, Al-Owaimer et al. (2013) found that the late-developing tissues such as internal fat and stomach compartments in goats, and tail fat in sheep (Al-Selbood, 2009) were proportionately more affected by the low plane of nutrition than the earlier-developing parts. However, it seems that the earlier-maturing tissues have a priority claim for the limited nutrients available in the blood stream when the growing lamb is insufficiently fed to provide all tissues with an adequate nutritive supply for normal growth. In this trial, it is clear that two weeks of ad libitum realimentation on the high concentrate diet were probably not enough time for stomach compartments, tail fat, subcutaneous fat, and visceral fat to recover the lost weights during restriction period. In addition, the general trend of tissue accretion suggests a different partitioning priority of nutrient intake between carcass and non-carcass components of realimented lambs, as indicated by an increase in weights of carcass, lean and liver at the expense of carcass and visceral fats. 
The increased weight of carcass lean in realimented lambs compared with control has been reported (Dashtizadeh et al., 2008; Al-Selbood, 2009). Rompala et al. (1985) noted a transitory increase in carcass lean weight during the early phase of realimentation. Feeding restriction treatments did not have any impacts on carcass bone weight. However, this result disagreed with Abouheif et al. (2013), who found that carcass bone weight from the 0.75 and 0.60 ad libitum treatments was $5-10 \%$ lower than those from ad libitum-fed lambs. The unchanged percentages of chemical constituents in separable lean between control, RR and R groups agreed with the results reported by Drouillard et al. (1991) and Sami et al. (2013). These results, however, disagreed with the conclusions of Marais et al. (1991) that the relationship of lean chemical composition was changed by feed restriction followed by realimentation, and that realimented lambs had more protein percentage than the control. The discrepancy may be related to the degree of lamb maturity. Turgeon et al. (1986) showed that, in young realimented lambs, a greater proportion of protein was made during the early period of the realimentation phase than in older lambs. However, there was a consensus that after the first period of realimentation is over, the chemical constituents of lean from the realimented lambs become similar in proportions to that of control-fed lambs (Al-Selbood, 2009).

\section{Conclusions}

Sheep production systems in Saudi Arabia depend mainly on imported feed ingredients that often have to be purchased at high prices. When integrating the feed restriction strategies into feeding management practices, the complimentary effects of compensatory growth improve feed efficiency and reduce carcass fatness without altering the final live body weight of lambs. In addition, the production of leaner carcasses, which meet a healthier option to the consumer demand, and the concomitant reduction of feeding costs may overcome the probable drop in carcass grade value. However, it is suggested that the implementation of $10 \%$ feed restriction followed by two weeks of realimentation just before slaughtering would be appreciated by both consumer and sheep producer and can thus be adopted as a nutritional practice for finishing and fattening Najdi lambs.

\section{Acknowledgments}

The authors would like to record their thanks to the Deanship of Scientific Research at King Saud University for funding this experiment through the research group project RGP-VPP-282.

\section{References}

Abouheif, M. A.; Al-Owaimer, A.; Kraidees, M.; Metwally, H. and Shafey, T. 2013. Effect of restricted feeding and realimentation on feed performance and carcass characteristics of growing lambs. Revista Brasileira de Zootecnia 42:95-101.

Al-Owaimer, A.; Suliman, G.; El-Waziry, A.; Metwally, H. and Abouheif, M. A. 2013. Allometric growth patterns of body and carcass components in Ardhi goat. International Journal of Animal and Veterinary Advances 5:183-189.

Al-Selbood, B. A. 2009. Effect of feeding program on performance and carcass characteristics of Najdi lambs. PhD thesis. King Saud University, Saudi Arabia.

AOAC - Association of Official Analytical Chemists. 1995. Official methods of analysis. 16th ed. Washington, DC, USA.

Atti, N. and Ben Salem, H. 2008. Compensatory growth and carcass composition of Barbarine lambs receiving different levels of feeding with partial replacement of the concentrate with feed blocks. Animal Feed Science and Technology 147:265-277.

Burrin, D. G.; Ferrell, C. L.; Elsemann, J. H.; Britton, R. A. and Nienaber, J. A. 1989. Effect of level of nutrition on splanchnic blood flow and oxygen consumption in sheep. British Journal of Nutrition 62:23-34.

Dashtizadeh, M.; Zamiri, M. J.; Kamalzadeh, A. and Kamali, A. 2008. Effect of feed restriction on compensatory growth response of young male goats. Iranian Journal of Veterinary Research 9:109-120.

Drouillard, J. S.; Klopfenstein, T. J.; Britton, R. A.; Bauer, M. L.; Gramlich, S. M.; Webster, T. J. and Ferrell, C. L. 1991. Growth, body composition and visceral organ mass and metabolism in lambs after protein or net energy restrictions. Journal of Animal Science 69:3357-3375.

Hambly, C. and Speakman, J. R. 2005. Contribution of different mechanisms to compensation for energy restriction in the mouse. Obesity Research 13:1548-1557.

Homem Junior, A. C.; Silva Sobrinho, A. G.; Yamamoto, S. M.; Pinheiro, R. S. B.; Buzzulini, C. and Lima, C. S. A. 2007. Ganho compensatório em cordeiras na fase de recria: desempenho e medidas biométricas. Revista Brasileira de Zootecnia 36:111-119.

Kamalzadeh, A.; Koops, W. J. and Kiasat, A. 2009. Effect of qualitative feed restriction on energy metabolism and nitrogen retention in sheep. South African Journal of Animal Science 39:30-39.

Mahouachi, M. and Atti, N. 2005. Effects of restricted feeding and re-feeding of Barbarine lambs: intake, growth and non-carcass components. Animal Science 81:305-312.

Marais, P. G.; van der Merwe, H. J. and du Toit, J. E. 1991. The effect of compensatory growth on feed intake, growth rate, body composition and efficiency of feed utilization in Dorper sheep. South African Journal of Animal Science 21:80-88.

Mora, O.; Shimada, A. and Ruiz, F. J. 1996. The effect of the length and severity of feed restriction on weight, carcass measurements and body composition of goats. Journal of Agriculture Science 127:549-553.

Rompala, R. E.; Jones, S. D. M.; Buchanan-Smith, J. G. and Bayley, H. S. 1985. Feedlot performance and composition of gain in late maturing steers exhibiting normal and compensatory growth. Journal of Animal Science 61:637-646.

Ryan, J.; Williams, I. H. and Moir, R. J. 1993. Compensatory growth in sheep and cattle. II. Changes in body composition and tissue weights. Australian Journal of Agricultural Research 44:1623-1633.

Sami, A.; Shafey, T. and Abouheif, M. A. 2013. Growth rate of carcass, non-carcass and chemical components of restricted fed and realimented growing lambs. International Journal of Agriculture and Biology 15:307-312. 
Shadnoush, G. R.; Alikhani, M.; Rahmani, H. R.; Edriss, M. A.; Kamalzadeh, A. and Zahedifar, M. 2011. Effects of restricted feeding and re-feeding in growing lambs: intake, growth and body organs development. Journal of Animal and Veterinary Advances 10:280-285.

Tolla, N.; Mirkena, T. and Yimegnuhal, A. 2003. Effect of feed restriction on compensatory growth of Arsi (Bos indicus) bulls. Animal Feed Science and Technology 103:29-39.

Tovar-Luna, I.; Goetsch, A. L.; Puchala, R.; Sahlu, T.; Carstens, G. E.; Freetly, H. C. and Johnson, Z. B. 2007. Effects of moderate feed restriction on energy expenditure by 2-year-old crossbred Boer goats. Small Ruminant Research 72:25-32.

Turgeon, O. A.; Brink, D. R.; Bartle, S. J.; Klopfenstein, T. J. and Ferrell, C. L. 1986. Effects of growth rate and compensatory growth on body composition in lambs. Journal of Animal Science 63:770-780.

Van Soest, P. J.; Robertson, J. B. and Lewis, B. A. 1991. Methods for dietary fiber, neutral detergent fiber and nonstarch polysaccharides in relation to animal nutrition. Journal of Dairy Science 74:3583-3597.

Wester, T. J.; Britton, R. A.; Klopfenstein, T. J.; Ham, G. A.; Hickok, D. T. and Krehbiel, C. R. 1995. Differential effects of plane of protein or energy nutrition on visceral organs and hormones in lambs. Journal of Animal Science 73:1674-1688.

Yambayamba, E. S. K.; Price, M. A. and Foxcroft, G. R. 1996. Hormonal status, metabolic changes and resting metabolic rate in beef heifers undergoing compensatory growth. Journal of Animal Science 74:57-69. 